\title{
Estimating Ultimate Recoveries of Unconventional Reservoirs: Knowledge Gained from the Developments Worldwide and Egyptian Challenges
}

\author{
Omar Mahmoud ${ }^{*}, 1$, Sarah A. Elnekhaily ${ }^{2}$, and Gehad Hegazy ${ }^{3}$ \\ 1Department of Petroleum Engineering, Future University in Egypt (FUE) \\ 2Department of Material Science and Engineering, Suez University \\ 3Department of Petroleum and Energy Engineering, American University in Cairo (AUC) \\ * Corresponding author: omar.mahmoud@ fue.edu.eg
}

\begin{abstract}
Supertight oil and gas reservoirs have always been considered uneconomical. Their high stimulation costs, forecasting the future production and estimating the ultimate recovery (EUR), have long been problematic. They should be constantly updated during the lifetime of a reservoir, besides; their accuracy depends on the amount of available data and the adopted method. However, after the enormous production in North America, exploring and developing unconventional hydrocarbon resources are gaining more interest worldwide. Nowadays, the Egyptian government is targeting tight layers/zones, in the western desert, to increase the high domestic energy demand and hence, increase the annual production of the conventional - high permeability - reservoirs. Several zones within Khatatba source rock in the Shoushan basin as well as in the Abu Gharadig basin are now being studied and evaluated to maximize their productivity and identify the optimal technology for future developments. In the present work, various approaches, used in predicting the performance of unconventional reservoirs, are investigated and compared through their forecasting future production and their estimated ultimate recovery (EUR). Traditional Arps' decline, for low permeability reservoirs, over-forecasts reserves. Power-law exponential decline (PLED), stretched-exponential decline (SEPD), logistic-growth model (LGM), and Duong's method have been used to represent the rate/time production data for the standard well completion in a multiple-fractured horizontal well in a shale play. These methods provide different forecasts as they are based on different equation forms. Unfortunately, previously mentioned methods are not satisfactorily adequate to forecast production for all unconventional reservoirs. The rate transient analytical (RTA) models require certain modifications of the reservoir and fracture parameters to provide optimistic EURs when compared to the numerical simulation.

In this research, based on the production forecast and EUR prediction, different models for forecasting unconventional well data have been reviewed and compared. Production data has been used to validate the accuracy of the models, show the similarity of reserves estimation, and reveal the relationship to the reservoir theory. This work might help the Egyptian operating companies to better understand the production dynamics of unconventional reservoirs and suggest a more reliable model EUR's estimation.
\end{abstract}

Keywords: Unconventional Reservoirs, Egyptian Challenges; EUR Prediction, Production Forecast; Decline Curve Analysis 


\section{1-Introduction}

Developments of unconventional reservoirs is a challenge. Knowledge about the properties and physical controlling flow parameters of formations as well as the long-term production performance is the main key element. Targeting a reliable production forecast of unconventional reserves requires using a combination of different methods. Among these methods are the Analogy (Type curves), the volumetric method, the material balance method, the decline curve analysis (DCA), the rate transient analysis (RTA), and the numerical simulation [24], [28]. In the following section, these methods are discussed briefly, pointing out their main ideas and the difficulties in estimating the EUR of such tight reserves.

The objective of this study is to review the used models and compare the different methods that are used for forecasting unconventional resources based on the goodness of fit, the similarity of reserves estimation, and the relationship to the reservoir physics. This review might help the Egyptian companies to better understand the production dynamics of unconventional reservoirs and suggest a more reliable and optimistic EURs estimation.

\section{2-Egyptian Petroleum And Natural Gas}

Egypt has been known as one of the pioneer African countries in the production of both oil and natural gas. According to the [49] it is classified as the largest non-OPEC oil producer in Africa and the third country in the production of natural gas within the same continent. Unfortunately, Egypt's oil reserves are decreased by about one billion barrels in 2016 [7]. Besides, the oil consumption rate is in a continuous increase, exceeding the production rate since $\sim$ year 2011 (Fig. 1). Comparable to the world's oil producers, Egypt suffers from the lack of new oil fields discoveries.

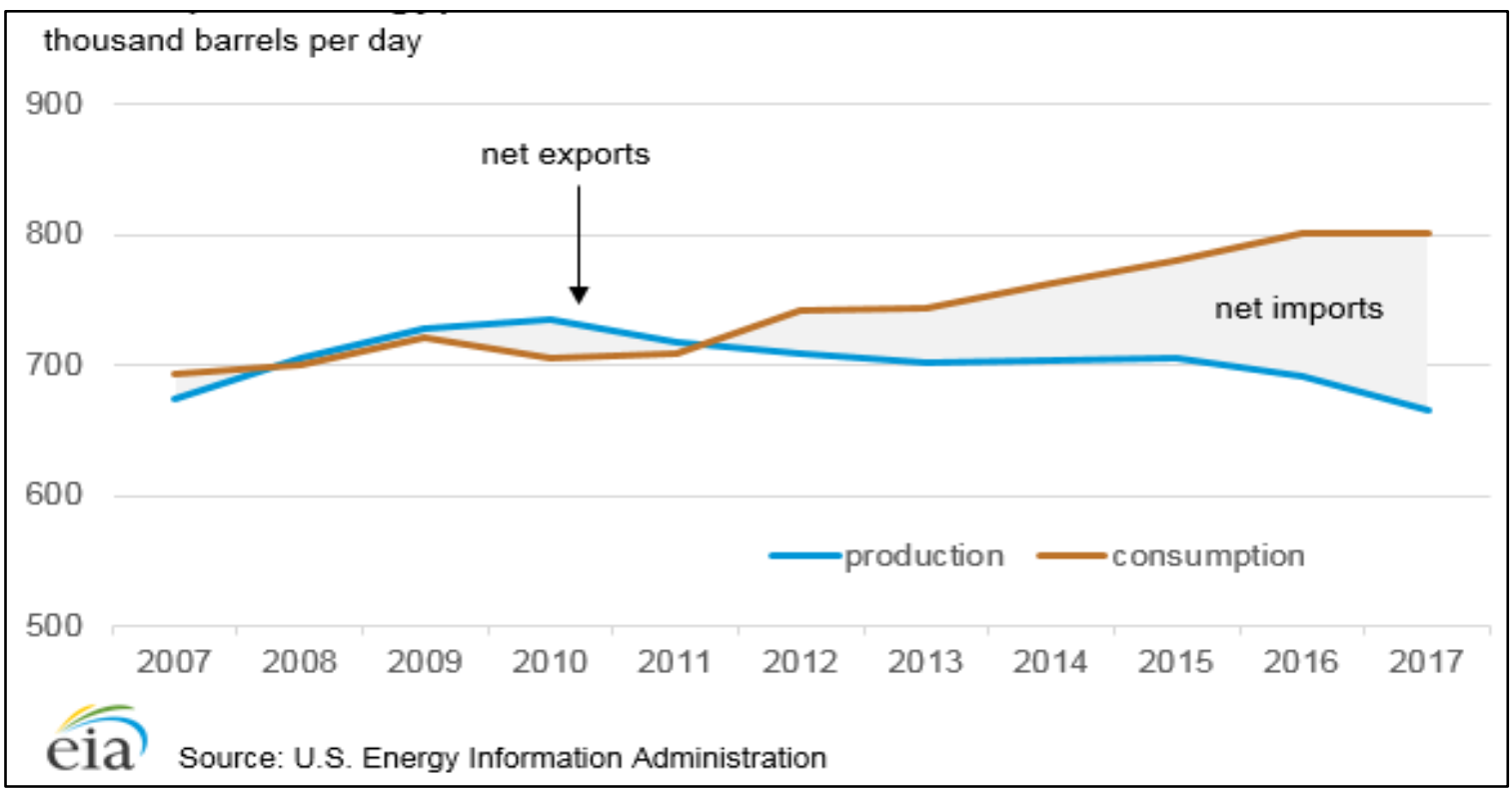

Fig. 1- Annual petroleum and other liquids production and consumption in Egypt (after US eia 2018).

On the other hand, as mentioned in the [49], Egypt became a net importer of natural gas in 2015 as a result of growing domestic demand over production levels (Fig. 2). Since then, several developments are carried out, by the government, in different gas fields such as Zohr and Atoll besides new projects such as the West Nile Delta (WND). Consequently, it is expected, within the next few years, that there will be a significant increase in Egypt's natural 
gas reserves providing recent discoveries.

Egypt is now targeting tight, unconventional layers/zones, such as Khatatba source rock in the Shoushan basin as well as in the Abu Gharadig basin in the Western Desert. Ongoing explorations and studies aim at identifying optimal technologies to maximize productivity of unconventional low-permeability reservoirs [30]. [41] and [42] summarized the findings of the recent activities within different unconventional plays in Egypt from which the basis for necessary subsequent development could be achieved.

The production of both oil and natural gas from unconventional resources has grown dramatically over the last two decades, especially in North America, through improving techniques of exploration and development [8], [15]. In 2018, The US production of petroleum and natural gas increased by $16 \%$ and $12 \%$, respectively, and these totals combined established a new production record [50]. The United States surpassed Russia in 2011 to become the world's largest producer of natural gas, and surpassed Saudi Arabia in 2018 to become the world's largest producer of petroleum (Fig. 3). U.S. natural gas production in 2018 was about 30.6 trillion cubic feet (Tcf), the highest annual amount recorded. Most of the production increases since 2005 are the result of horizontal drilling and hydraulic fracturing techniques, notably in shales and other tight geologic formations.

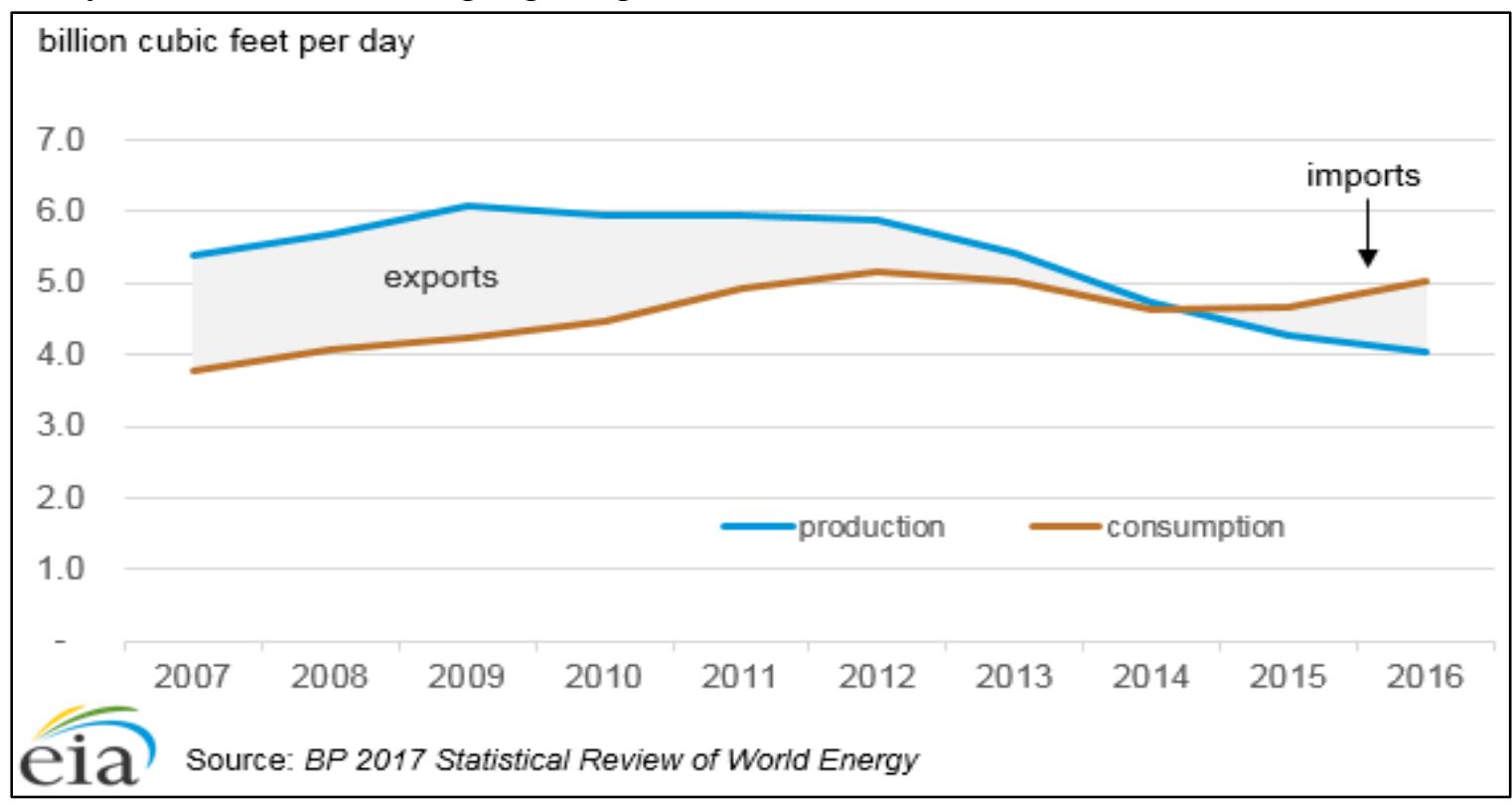

Fig. 2- Dry natural gas production and consumption in Egypt (after US eia 2018).

\section{3-Analogy (Type Curves)}

Analogy/analogies can be defined as an identifying of similarities between two things by using logical comparison. So that, Analog data points to existing reservoirs and wells that have like properties can lead to a reliable future production forecast and reserves estimation. It helps in reducing uncertainty while running those kinds of prediction.

Based on the Society of Petroleum Engineers (SPE) and the United States Securities and Exchange Commission (SEC)' definition of an analog, an analog should have the same geographic, geological, shale and fluid characteristics [22]. Besides, different criteria regarding depletion stage, completion techniques and controlling properties, of both an analog and a target should be satisfied [27]. 


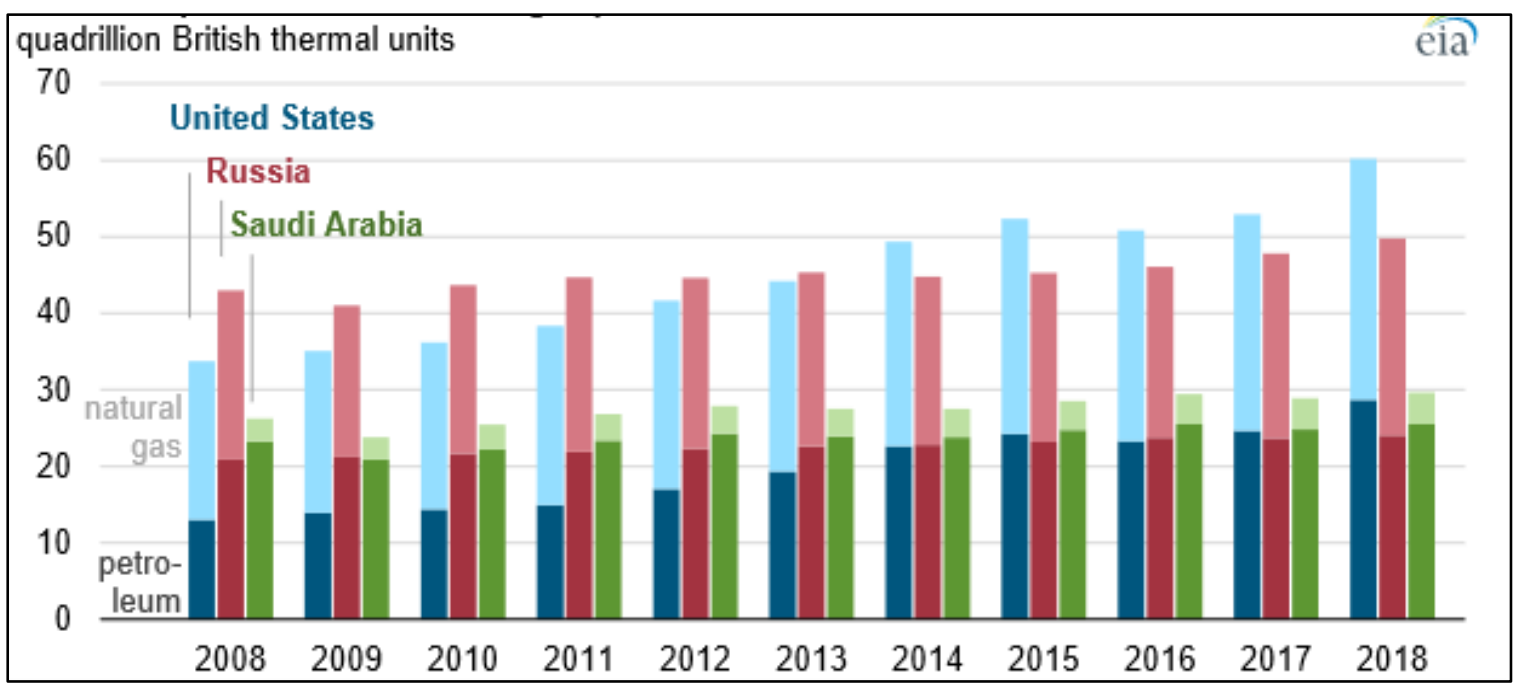

Fig. 3- Estimated petroleum and natural gas production in U.S., Russia, and Saudi Arabia (after US eia 2019).

\section{4-Volumetric Estimations}

In this method the EUR can be estimated as a fraction of the existing hydrocarbon in place, which could be done through simple calculations that rely on the recovery factor [18]. One of these equations is given below (Eq. 1) in which the EUR can be calculated as follows:

$$
E U R=\frac{A h \phi\left(1-S_{w i}\right)}{B i} \times R F,
$$

where $\mathrm{A}=$ reservoir drainage area, $\mathrm{h}=$ reservoir thickness, $\phi=$ porosity, Swi $=$ connate or irreducible water saturation, $\mathrm{Bi}=$ initial formation volume factor, and $\mathrm{RF}$ is the recovery factor.

Despite the difficulty in accurately determining the net-pay thickness [44] additional gas volumes in the pore spaces [39], [40] and the amount of recoverable gas in unconventional tight reservoirs, the volumetric method is still regarded as simple and essential in reserves estimation and production forecast.

\section{5-Material Balance Calculations}

The main idea of the material balance is to determine the initial volume of hydrocarbons in the reservoir and its current volume then equate their difference with the total production. It assumes an unchanged drainage volume and a stabilized boundary-dominated flow (BDF). The problem arises when dealing with unconventional reserves which requires longer times for volumetric behavior stabilization. the longer time will assure a sufficient pressure production data and reservoir fluid behavior (PVT) data [43],[19], [20]. A straight-line plot between the reservoir pressure/gas compressibility factor ratio $(\mathrm{p} / \mathrm{z})$ versus cumulative gas production is mostly common in estimating the gas in place at $\mathrm{p} / \mathrm{z}=0$ (Fig. 4, based on Eq. 2).

$$
\frac{p}{z}=\frac{p_{i}}{z_{i}}\left(1-\frac{G_{p}}{G}\right)
$$


where $\mathrm{p}=$ reservoir pressure, $\mathrm{z}=$ gas compressibility factor, $\mathrm{Gp}=$ cumulative gas produced (volume), $\mathrm{G}=$ gas in place (volume), and the subscript " $\mathrm{i}$ " represents the initial reservoir conditions.

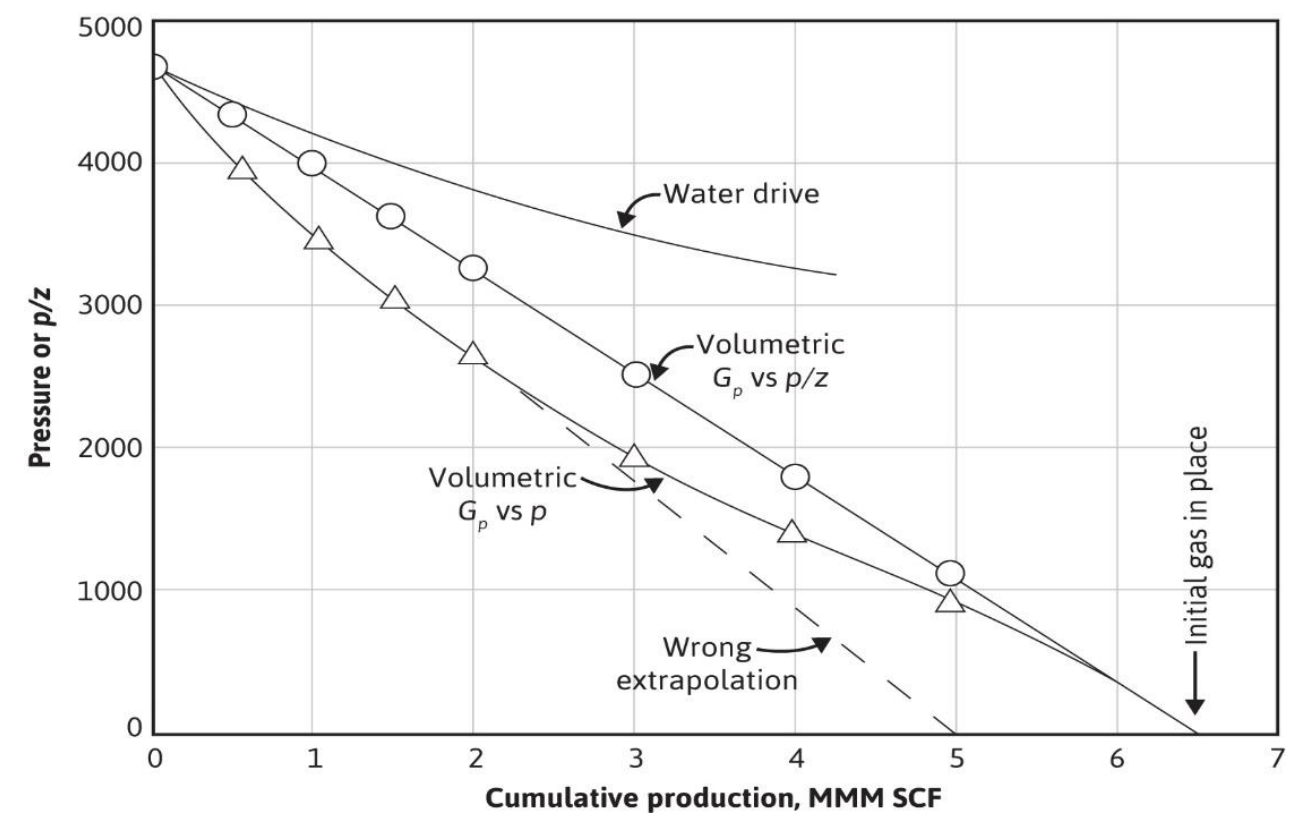

Fig. 4- Schematic illustration of the p/z versus cumulative gas production plot.

The assumptions of this method like unchanging drainage volume and a stabilized BDF are not satisfied in the case of unconventional gas reservoirs. So that, the p/z-plot analysis in this case can provide reasonable assessments for planning purposes with other methods.

\section{6-Decline Curve Analysis}

Analyzing techniques are commonly used for conventional reserves to estimate the future performance and determining the EUR. It has been the most widely used approach in the field of analyzing the decline rates, forecasting the future performance, and determining EUR. This could be done either through the Arps' decline model [2], or type-curve matching techniques [13], [14], [35], [1] by matching the predetermined type curves by the early production data from producing wells. The Arps' model has proven to work very well in conventional oil and gas wells. However, it has not been proven to work well when used with the extremely lowpermeability reservoirs.

As reported in [2] the empirical equation of Arps' model can be put as in Eq. 3, that could represent three different forms of conventional reservoirs depending on the value of $b$ (the dimensionless decline curve exponent) which is $0 \leq \mathrm{b} \leq 1$. Table 1 shows a summary of Arps' decline curve relations and their characteristics.

$$
q=\frac{q_{i}}{\left(1+b D_{i} t\right)^{(1 / b)}}
$$

where $\mathrm{q}$ is the production rate at time $\mathrm{t}$ (volume/time), $\mathrm{qi}=$ the initial production rate (volume/time), Di = Arps' initial decline rate (1/time), b = Arps' decline curve exponent (dimensionless). 
Table 1-Summary of Arps' traditional decline curve relations (modified after [28]).

\begin{tabular}{|c|c|c|}
\hline $\begin{array}{l}\text { Exponential } \\
\text { Decline }\end{array}$ & Hyperbolic Decline & Harmonic Decline \\
\hline $\mathrm{b}=0$ & $0<\mathrm{b}<1$ & $b=1$ \\
\hline Di is constant & $\begin{array}{l}\text { Di is proportional to a } \\
\text { fractional power of the } \\
\text { production rate }\end{array}$ & $\begin{array}{l}\mathrm{Di} \text { is proportional to } \\
\text { production rate }\end{array}$ \\
\hline$q=q_{i} e^{-D_{i} t}$ & $q=\frac{q_{i}}{\left(1+b D_{i} t\right)^{(1 / b)}}$ & $q=\frac{q_{i}}{\left(1+D_{i} t\right)}$ \\
\hline$Q=-\frac{1}{D_{i}} q+\frac{q_{i}}{D_{i}}$ & $\begin{array}{r}Q=\frac{q_{i}^{b}}{D_{i}(b-1)}\left[q^{(1-b)}\right. \\
\left.-q_{i}^{(1-b)}\right]\end{array}$ & $Q=\frac{q_{i}}{D_{i}}\left[\ln q_{i}-\ln q\right]$ \\
\hline $\begin{array}{l}\text { Straight line when } \\
\text { plotting: } \\
\text { log } q \text { versus } t, \text { or } \\
q \text { versus } Q\end{array}$ & $\begin{array}{l}\text { Straight line when plotting: } \\
q /(d q / d t) \text { versus } t\end{array}$ & $\begin{array}{l}\text { Straight line when } \\
\text { plotting: } \\
\log q \text { versus } \log t, \text { or } \\
\log q \text { versus } \log Q\end{array}$ \\
\hline
\end{tabular}

However, when dealing with unconventional reservoirs, a b-value greater than one is experienced, and thus, this causes an over-forecasting of reserves. The Arps' equations then become inadequate for reserves estimation. Recently, different techniques have been developed to model the decline behavior in unconventional plays [25], [26], [51], [9], [11], [36], [53] and provide the best equation for calculating the dimensionless decline rate (Eq. 4). [24] gave a good summary of the decline rate calculations in different methods (Table 2).

$q=q_{i} \propto(t)$

where $\propto(t)=$ the decline rate (dimensionless).

Table 2- Summary of decline rate relations for DCA of unconventional gas reservoirs (modified after [24]).

\begin{tabular}{|c|c|c|c|}
\hline Method & Decline Rate & Reference & \\
\hline $\begin{array}{l}\text { Stretched Exponential } \\
\text { Decline }\end{array}$ & $\propto(t)=\exp \left[-\left(\frac{t}{\tau}\right)^{n}\right]$ & {$[51]$} & \\
\hline Power Law Decline & $\propto(t)=\exp \left(-D_{\infty}-\frac{D_{l}}{n} t^{n}\right)$ & {$[25],[26]$} & \\
\hline Duong's Model & $\begin{array}{c}\propto(t)=t^{-m} \exp \left[\frac{a}{1-m}\left(t^{1-m}\right.\right. \\
-1)]\end{array}$ & {$[11]$} & \\
\hline Logistic Growth Decline & $\propto(t)=\frac{n a t^{n-1}}{\left(a+t^{n}\right)^{2}}$ & [9] & \\
\hline Probabilistic Decline & $\propto(t)=e^{-a e^{-b t}}$ & $\begin{array}{l}\text { [17] and } \\
(2013)\end{array}$ & Blasingame \\
\hline $\begin{array}{l}\text { Extended Exponential } \\
\text { Decline }\end{array}$ & $\propto(t)=e^{-\left(\beta_{l}+\beta_{e} e^{-t^{n}}\right) t}$ & [53] & \\
\hline
\end{tabular}


Recently, different trails had been accomplished in order to develop a more conservative DCA model that can lead to more confident forecasts [10], [29], [48]. DCA is a powerful tool and can be used as a standalone way for forecasting future performance of unconventional reservoirs of predicting EUR's.

\section{7-Rate Transient Analysis And Numerical Simulation}

Compared to the DCA model, the rate transient analysis (RTA) is more attractive for tight and unconventional reservoirs. Its main idea is based on analyzing daily production data and matching them with analytical models [54]. The analytical models developed depend on the characteristics of the production flow rate. For example [12],[52],[5] established their analytical model for long-term transient linear flow reserves, whereas, [3],[4] presented a transient analysis of tight gas reservoirs that have long-term linear and bilinear flows. For the multilayer unconventional gas reservoirs, [45], [46] presented a model that can be used for matching production data.

There is an ongoing development in analytical models that can be adopted for forcasting production and estimating the EUR of unconventional reserves [6], [31], [32], [37], [38], He et al. 2018). Fig. 5 shows the log-log diagnostic, standard, and dynamic drainage area (DDA)corrected linear flow plots of a tight/shale gas reservoir case using an analytical model developed by [37].
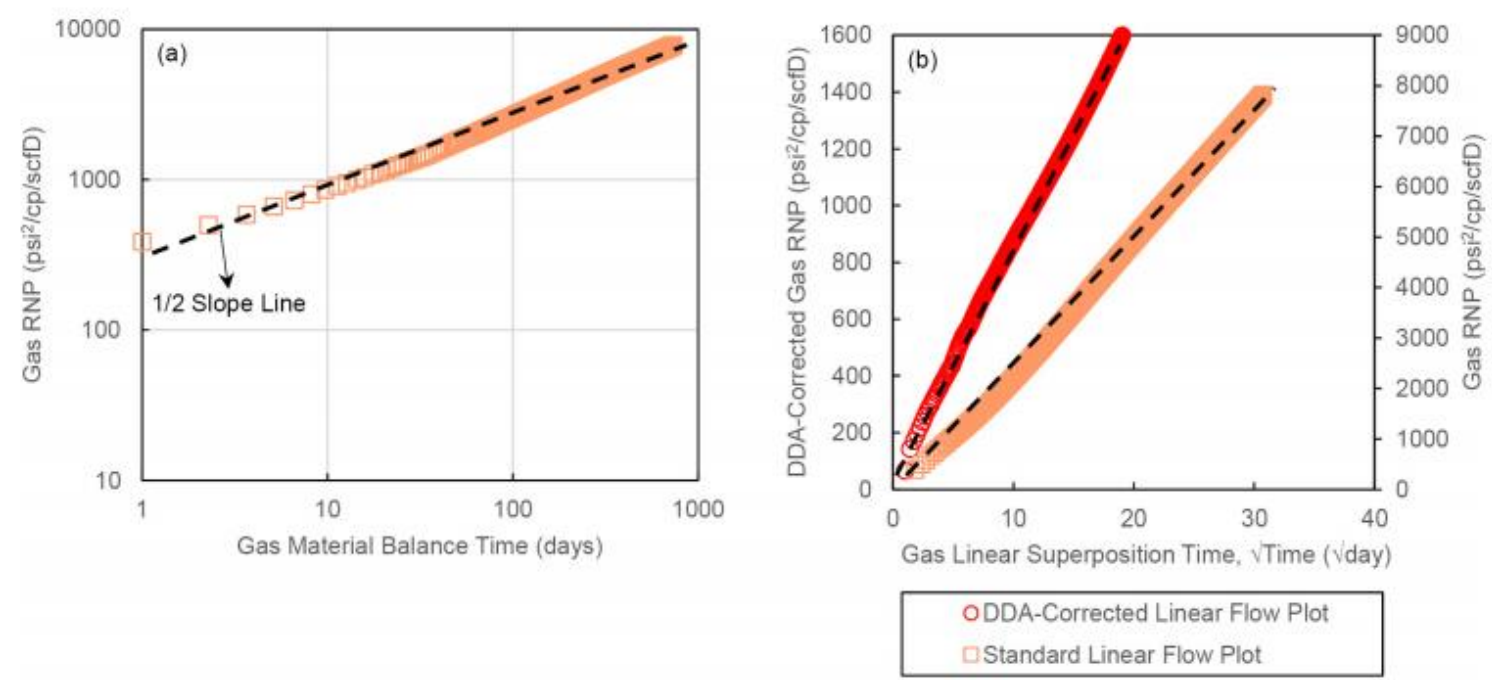

Fig. 5: Log-log diagnostic, standard, and dynamic drainage area (DDA)-corrected linear flow plots of a tight/shale gas reservoir case (modified after [37])

Despite their availability in different commercial software, the RTA application, with unconventional reservoirs, is still facing different challenges. One of these challenges is the limitations of the analytical and semi-analytical models [23], especially for tight/shale gas systems.

Recently numerical simulation is found to be a vital tool in understanding of the flow behavior characteristics in tight/shale gas systems. Although facing nearly the same difficulties and limitations of analytical analysis, their ongoing developments are promising in helping in the optimization of lateral length, well spacing, and completion techniques as well as getting 
valuable reserves estimation [16], [33], [47], [34].

\section{8-Conclusions And Recommendations}

The breakthrough in the oil/gas production from tight/unconventional reservoirs in North America, led different countries, all over the world, to target their tight, unconventional layers/zones. In Egypt there is an ongoing exploration in Khatatba source rock in the Shoushan basin as well as in the Abu Gharadig basin in the Western Desert. Egypt aims at identifying optimal technologies to maximize productivity of unconventional low-permeability reservoirs. It is expected, within the next few years, that there will be a significant increase in Egypt's natural gas reserves providing recent discoveries.

In this paper, various approaches, currently used in predicting the performance of unconventional reservoirs, are investigated and compared through their forecasting future production and their estimated ultimate recovery (EUR). This might help the Egyptian operating companies to better understand the production dynamics of unconventional reservoirs and suggest a more reliable model EUR's estimation.

Traditional Arps' decline, for low permeability reservoirs, is found inadequate. Thus, different other methods and relations have been used to represent the rate/time production data in tight/shale gas plays. The recent developments are leading to more conservative and confident DCA models forecasts that are based on different equation forms.

Analytical, semi-analytical models, numerical models, and history matching of production data using RTA are widely used for forecasting future performance and estimating reserves of unconventional reservoirs. The commercial software's for this type of modeling exist in large quantities. Rate transient analytical (RTA) models require certain modifications of the reservoir and fracture parameters to provide optimistic EURs when compared to the numerical simulation. They are important tools that can be used - in parallel with other methods - for production forecasting and EUR prediction of unconventional reservoirs.

Analogy and volumetric calculations are both important methods for EUR prediction of unconventional reservoirs and should be attempted whenever possible. Both can be used to provide valuable uncertainty estimations with other methodologies. However, they can't be used as standalone analysis for predicting accurate EUR and forecasting future performance.

\section{9-Acknowledgements}

The authors would like to express their sincere thanks and appreciation to the Future University in Egypt (FUE) and the American University in Cairo (AUC) for their continuous encouragement and support.

\section{References}

[1] Agarwal, R. G., Gardner, D. C., Kleinsteiber, S. W. et al. Analyzing Well Production Data Using CombinedType-Curve and Decline-Curve Analysis Concepts. SPE Res Eval \& Eng 2 (5): 478-486. SPE-57916-PA, 1999. https://doi.org/10.2118/57916-PA.

[2] Arps, J. J. Analysis of Decline Curves. SPE-945228-G. Trans., AIME, 160: 228-247, 1945. https://doi.org/10.2118/945228-G.

[3] Arévalo-Villagrán, J. A., Cinco-L, H., Wattenbarger, R. A et al. Transient Analysis of Tight Gas Well Performance. Presented at the SPE Annual Technical Conference and Exhibition, Denver, Colorado, USA, 5-8 October 2003. SPE-84476-MS. https://doi.org/10.2118/84476-MS. 
[4] Arévalo-Villagrán, J. A., Ganpule, S. V., and Wattenbarger, R. A. Analysis of Long-Term Performance in Tight Gas Wells: Field Examples. Presented at the SPE International Petroleum Conference and Exhibition in Mexico, Villahermosa, Mexico, 10-12 February . 2002. SPE-74360-MS. https://doi.org/10.2118/74360MS.

[5] Arévalo-Villagrán, J. A., Wattenbarger, R. A., Samaniego-V, F. et al. Production Analysis of Long-Term Linear Flow in Tight Gas Reservoirs: Case Histories. Presented at the SPE Annual Technical Conference and Exhibition, New Orleans, Louisiana, USA, 30 September-3 October . 2001. SPE-71516-MS. https://doi.org/10.2118/71516-MS.

[6] Bello, R. O. and Wattenbarger, R. A. Rate Transient Analysis in Naturally Fractured Shale Gas Reservoirs. Presented at the CIPC/SPE Gas Technology Symposium Joint Conference, Calgary, Alberta, Canada, 1619 June 2008. SPE-114591-MS. https://doi.org/10.2118/114591-MS.

[7] BP 2017 Statistical Review of World Energy, historical database. https://www.bp.com/en/global/corporate/energy-economics/statistical-review-of-world-energy.html.

[8] Chen, Z., Liao, X., Zhao, X. et al. Performance of Horizontal Wells with Fracture Networks in Shale Gas Formation. J. Pet. Sci. Eng. 133: 646-664, 2015. https://doi.org/10.1016/j.petrol.2015.07.004.

[9] Clark, A. J., Lake, L. W. and Patzek, T. W. Production Forecasting with Logistic Growth Model. Presented at the SPE Annual Technical Conference and Exhibition, Denver, Colorado, USA, 30 October-2 November 2011. SPE-144790-MS. https://doi.org/10.2118/144790-MS.

[10] de Holanda, R. W., Gildin, E., and Valco, P. P. Combining Physics, Statistics, and Heuristics in the DeclineCurve Analysis of Large Data Sets In Unconventional Reservoirs. SPE Res Eval \& Eng. SPE-185589-PA (in press; posted January 2018). https://doi.org/10.2118/185589-PA.

[11] Duong, A. N. 2011. Rate-Decline Analysis for Fracture-Dominated Shale Reservoirs. SPE Res Eval \& Eng 14 (3): 377-387. SPE-137748-PA. https://doi.org/10.2118/137748-PA.

[12]El-Banbi, A. H. and Wattenbarger, R. A. Analysis of Linear Flow in Gas Well Production. Presented at the SPE Gas Technology Symposium, Calgary, Alberta, Canada, 15-18 March 1998. SPE-39972-MS. https://doi.org/10.2118/39972-MS.

[13]Fetkovich, M. J. 1980. Decline Curve Analysis Using Type Curves. J Pet Technol 32 (6): 1065-1077. SPE4629-PA. https://doi.org/10.2118/4629-PA.

[14]Fetkovich, M. J., Vienot, M. E., Bradley, M. D. et al. Decline Curve Analysis Using Type Curves: Case Histories. SPE Form Eval 2 (4): 478-486. SPE-13169-PA, 1987. https://doi.org/10.2118/13169-PA.

[15] Figueiredo, B., Tsang, C-F, Rutqvist, J. et al. Study of Hydraulic Fracturing Processes in Shale Formations with Complex Geological Settings. J. Pet. Sci. Eng. 152: 361-374, 2017. https://doi.org/10.1016/j.petrol.2017.03.011.

[16] Freeman, C. M., Moridis, G. J., Ilk, D. et al. A Numerical Study of Performance for Tight Gas and Shale Gas Reservoir Systems. Presented at the SPE Annual Technical Conference and Exhibition, New Orleans, Louisiana, USA, 4-7 October 2009. SPE-124961-MS. https://doi.org/10.2118/124961-MS.

[17] Fulford, D. S. and Blasingame, T. A. Evaluation of Time-Rate Performance of Shale Wells using the Transient Hyperbolic Relation. Presented at the SPE Unconventional Resources Conference Canada, Calgary, Alberta, Canada, 5-7 November . 2013. SPE-167242-MS. https://doi.org/10.2118/167242-MS.

[18] Garb, F. A. Oil and Gas Reserves Classification, Estimation, and Evaluation. J Pet Technol 37 (3): $373-390$. SPE-13946-PA, 1985. https://doi.org/10.2118/13946-PA.

[19] Havlena, D. and Odeh, A. S. The Material Balance as an Equation of a Straight Line. J Pet Technol 15 (8): 896-900. SPE-559-PA, 1963. https://doi.org/10.2118/559-PA.

[20] Havlena, D. and Odeh, A. S. The Material Balance as an Equation of a Straight Line-Part II, Field Cases. J Pet Technol 16 (7): 815-822. SPE-869-PA, 1964. https://doi.org /10.2118/869-PA.

[21] He, Y., Cheng, S., Rui, Z. et al. An Improved Rate-Transient Analysis Model of Multi-Fractured Horizontal Wells with Non-Uniform Hydraulic Fracture Properties. Energies 11 (2): 393, $2018 . \quad$ Doi: 10.3390/en11020393.

[22] Hodgin, J. E. and Harrell, D. R. The Selection, Application, and Misapplication of Reservoir Analogs for the Estimation of Petroleum Reserves. Presented at the SPE Annual Technical Conference and Exhibition, San Antonio, Texas, USA, 24-27 September 2006. SPE-102505-MS. https://doi.org/10.2118/102505-MS.

[23] Houzé, O., Tauzin, E., Artus, V. et al. The Analysis of Dynamic Data in Shale Gas Reservoirs-Part 1. Company report, Kappa Engineering, Houston, Texas, 2010.

[24] Ibrahim, M., Mahmoud, O., and Pieprzica, C. A New Look at Reserves Estimation of Unconventional Gas Reservoirs. Presented at the 6th SPE/AAPG/SEG Unconventional Resources Technology Conference (URTeC), Houston, Texas, USA, 23-28 July 2018. URTEC-2903130-MS. https://doi.org/10.15530/URTEC-2018-2903130.

[25]Ilk, D., Perego, A. D., Rushing, J. A. et al. Integrating Multiple Production Analysis Techniques To Assess Tight Gas Sand Reserves: Defining a New Paradigm for Industry Best Practices. Presented at the CIPC/SPE 
Gas Technology Symposium, Calgary, Alberta, Canada,16-19 June 2008b. SPE-114947-MS. https://doi.org/10.2118/114947-MS.

[26]Ilk, D., Rushing, J. A., Perego, A. D. et al. Exponential vs. Hyperbolic Decline in Tight Gas Sands: Understanding the Origin and Implications for Reserve Estimates Using Arps' Decline Curves. Presented at the SPE Annual Technical Conference and Exhibition, Denver, Colorado, USA, 21-24 September 2008 a. SPE-116731-MS. https://doi.org/10.2118/116731-MS.

[27] Lee, J. and Sidle, R. Gas-Reserves Estimation in Resource Plays. SPE Econ \& Mgmt 2 (2): 86-91. SPE130102-PA, 2010. https://doi.org/10.2118/130102-PA.

[28] Mahmoud, O., Ibrahim, M., Pieprzica, C. et al. EUR Prediction for Unconventional Reservoirs: State of the Art and Field Case. Presented at the SPE Trinidad and Tobago Section Energy Resources Conference, Port of Spain, Trinidad and Tobago, 25-27 June 2018. SPE-191160-MS. https://doi.org/10.2118/191160-MS.

[29] Miao, Y., Li, X., Lee, J. et al. A New Rate-Decline Analysis of Shale Gas Reservoirs: Coupling the SelfDiffusion and Surface Diffusion Characteristics. J. Pet. Sci. Eng. 163: 166-176, 2018. https://doi.org/10.1016/j.petrol.2017.12.097.

[30] Mohamed, M. S., Abdel Meguid, A., Wang, Q. et al. Lessons Learned From Hydraulic Fracturing the First Exploratory Shale Gas Well in Egypt. Presented at the SPE Asia Pacific Hydraulic Fracturing Conference, Beijing, China, 24-26 August 2016. SPE-181870-MS. https://doi.org/10.2118/181870-MS.

[31] Nobakht, M. and Clarkson, C. R. A New Analytical Method for Analyzing Linear Flow in Tight/Shale Gas Reservoirs: Constant-Rate Boundary Condition. SPE Res Eval \& Eng 15 (1): 51-59. SPE-143990-PA, 2012. https://doi.org/10.2118/143990-PA.

[32] Nobakht, M., Clarkson, C. R., and Kaviani, D. New and Improved Methods for Performing Rate-Transient Analysis of Shale Gas Reservoirs. SPE Res Eval \& Eng 15 (3): 335-350. SPE-147869-PA, 2012. https://doi.org/10.2118/147869-PA.

[33] Olorode, O., Freeman, C. M., Moridis, G. et al. High-Resolution Numerical Modeling of Complex and Irregular Fracture Patterns in Shale-Gas Reservoirs and Tight Gas Reservoirs. SPE Res Eval \& Eng 16 (4): 1-13. SPE-152482-PA, 2013. https://doi.org/10.2118/152482-PA.

[34] Olorode, O. M., Akkutlu, I. Y., and Efendiev, Y. Compositional Reservoir-Flow Simulation for OrganicRich Gas Shale. SPE J. 22 (6): 1963-1983. SPE-182667-PA, 2017. https://doi.org/10.2118/182667-PA.

[35] Palacio, J. C. and Blasingame, T. A. Decline-Curve Analysis with Type Curves-Analysis of Gas Well Production Data. Oral presentation given at the Rocky Mountain Regional/Low Permeability Reservoirs Symposium and Exhibition, Denver, Colorado, USA, 12-14 April 1993. SPE-25909-MS. https://doi.org/10.2118/25909-MS

[36] Patzek, T. W., Male, F., and Marder, M. Gas Production in the Barnet Shale Obeys a Simple Scaling Theory. Proc. Natl. Acad. Sci. U.S.A. 110 (49): 19731-19736, 2013. https://doi.org/10.1073/pnas.1313380110.

[37] Qanbari, F. and Clarkson, C. R. Rate-Transient Analysis of Liquid-Rich Tight/Shale Reservoirs Using the Dynamic Drainage Area Concept: Examples from North American Reservoirs. Presented at the SPE Low Perm Symposium, Denver, Colorado, USA, 5-6 May 2016. SPE-180230-MS. https://doi.org/10.2118/180230-MS.

[38] Qanbari, F., Clarkson, C. R., and Shahamat, M. S. Incorporation of Formation Water into Rate-Transient Analysis of Tight Oil Wells with High Water-Oil Ratio: A Field Example from North America. Presented at the SPE Western Regional Meeting, Bakersfield, California, USA, 23-27 April 2017. SPE-185745-MS. https://doi.org/10.2118/185745-MS.

[39] Ross, D. J. K. and Bustin, R. M. Shale Gas Potential of the Lower Jurassic Gordondale Member, Northeastern British Columbia, Canada. Bulletin of Canadian Petroleum Geology 55 (1): 51-75, 2007. https://doi.org/10.2113/gscpgbull.55.1.51.

[40] Ross, D. J. K. and Bustin, R. M. Characterizing the shale gas resource potential of Devonian-Mississippian strata in the Western Canada sedimentary basin: Application of an integrated formation. AAPG Bulletin 92 (1): 87-125, 2008. https://doi.org/10.1306/09040707048.

[41] Salah, M. and Ibrahim, M. Unconventional Reservoir Development in Egypt's Western Desert: Lessons Learned From the First Appraisal Wells. Presented at the 6th SPE/AAPG/SEG Unconventional Resources Technology Conference (URTeC), Houston, Texas, USA, 23-28 July 2018. URTEC-2903130-MS. https://doi.org/10.15530/URTEC-2018-2902739.

[42] Salah, M., Orr, D., Abdel Meguid et al. Multistage Horizontal Hydraulic Fracture Optimization Through an Integrated Design and Workflow in Apollonia Tight Chalk, Egypt from the Laboratory to the Field. Presented at the Abu Dhabi International Petroleum Exhibition \& Conference (ADIPEC), Abu Dhabi, UAE, 7-10 November 2016. SPE-181870-MS. https://doi.org/10.2118/183068-MS.

[43] Schilthuis, R. J. Active Oil and Reservoir Energy. SPE-936033-G. Trans., AIME, 118: 33-52, 1936. https://doi.org/10.2118/936033-G. 
[44] Shanley, K. W., Cluff, R. M., and Robinson, J. W. Factors Controling Profilic Gas Production from LowPermeability Sandstone Reservoirs: Implifications for Resource Assessment, Prospect Development, and Risk Analysis. AAPG Bulletin 88 (8): 1083-1121, 2004. Doi: 10.1306/03250403051.

[45] Spivey, J. P. Estimating Layer Properties for Wells in Multilayer Low-Permeability Gas Reservoirs by Automatic History Matching Production and Production Log Data. Presented at the SPE Gas Technology Symposium, Calgary, Alberta, Canada, 15-17 May 2006. SPE-100509-MS. https://doi.org/10.2118/100509MS.

[46] Spivey, J. P. Production Data Analysis for Commingled Multilayer Gas Reservoirs-Graphical Aides for Flow Regime Identification and History Matching. Presented at the SPE Hydraulic Fracturing Technology Conference, College Station, Texas, USA, 29-31 January 2007. SPE-106305-MS. https://doi.org/10.2118/106305-MS.

[47] Sun, H., Chawathe, A., Hoteit, H. et al. Understanding Shale Gas Flow Behavior Using Numerical Simulation. SPE J. 20 (1): 142-154. SPE-167753-PA, 2015. https://doi.org/10.2118/167753-PA.

[48] Tugan, M., F. and Weijermars, R. Improved EUR Prediction for Multi-Fractured Hydrocarbon Wells Based on 3-Segment DCA: Implications for Forecasting of Parent and Child Wells. J. Pet. Sci. Eng. In Press; posted online Nov. 15), 2019. https://doi.org/10.1016/j.petrol.2019.106692.

[49] U.S. Energy Information Administration. Country Analysis Brief: Egypt, May, 24, 2018, https://www.eia.gov/beta/international/analysis_includes/countries_long/Egypt/egypt.pdf.

[50] U.S. Energy Information Administration. Frequently Asked Questions, November 6, 2019, https://www.eia.gov/tools/faqs/faq.php?id=709\&t=6.

[51] Valkó, P. P. Assigning Value to Stimulation in the Barnett Shale: A Simultaneous Analysis of 7000 Plus Production histories and Well Completion Records. Presented at the SPE Hydraulic Fracturing Technology Conference, The Woodlands, Texas, USA, 19-21 January 2009. SPE-119369-MS. https://doi.org/10.2118/119369-MS.

[52] Wattenbarger, R. A., El-Banbi, A. H., Villegas, M. E. et al. Production Analysis of Linear Flow into Fractured Tight Gas Wells. Presented at the SPE Rocky Mountain Regional/Low-Permeability Reservoirs Symposium, Denver, Colorado, USA, 5-8 April 1998. SPE-39931-MS. https://doi.org/10.2118/39931-MS.

[53]Zhang, H., Cocco, M., Rietz, D. et al. An Empirical Extended Exponential Decline Curve for Shale Reservoirs. Presented at the SPE Annual Technical Conference and Exhibition, Houston, Texas, USA, 2830 September 2015. SPE-175016-MS. https://doi.org/10.2118/175016-MS.

[54]Zuo, L., Yu, W., and Wu, K. A Fractional Decline Curve Analysis Model for Shale Gas Reservoirs. Int. J. Coal Geol. 163: 140-148, 2016. https://doi.org/10.1016/j.coal.2016.07.006. 